\title{
Coriolus versicolor biomass increases dendritic arborization of newly-generated neurons in mouse hippocampal dentate gyrus
}

\author{
Elisabete Ferreiro ${ }^{1,2,4, *}$, Inês R. Pita ${ }^{3,4, *}$, Sandra I. Mota ${ }^{1,2,4}$, Jorge Valero ${ }^{5,6}$, Nuno R. \\ Ferreira7, Tito Fernandes $^{8,9}$, Vittorio Calabrese ${ }^{10}$, Carlos A. Fontes-Ribeiro ${ }^{3,4}$, Frederico \\ C. Pereira ${ }^{3,4}$ and Ana Cristina Rego ${ }^{1,4,11}$ \\ ${ }^{1}$ CNC-Center for Neuroscience and Cell Biology, University of Coimbra, Coimbra, Portugal \\ ${ }^{2}$ III-Institute for Interdisciplinary Research (IIIUC), University of Coimbra, Coimbra, Portugal \\ ${ }^{3}$ Institute of Pharmacology and Experimental Therapeutics/IBILI, Faculty of Medicine, University of Coimbra, Coimbra, \\ Portugal \\ ${ }^{4}$ CNC.IBILI-University of Coimbra, Coimbra, Portugal \\ ${ }^{5}$ Achucarro Basque Center for Neuroscience, Science Park of the University of the Basque Country (UPV/EHU), Leioa, Spain \\ ${ }^{6}$ Ikerbasque Basque Foundation for Science, Bilbao, Bizkaia, Spain \\ ${ }^{7}$ Faculty of Pharmacy, University of Coimbra, Coimbra, Portugal \\ ${ }^{8}$ Ministry of Education, Maputo, Mozambique \\ ${ }^{9}$ Faculty of Veterinary Medicine, Lisbon University, Lisbon, Portugal \\ ${ }^{10}$ Department of Biomedical and Biotechnological Sciences, School of Medicine, University of Catania, Catania, Italy \\ ${ }^{11}$ Institute of Biochemistry, Faculty of Medicine, University of Coimbra, Coimbra, Portugal \\ *These authors contributed equally to this work \\ Correspondence to: Frederico C. Pereira, email: fredcp@ci.uc.pt \\ Ana Cristina Rego, email: a.cristina.rego@gmail.com
}

Keywords: coriolus versicolor; cognitive reserve; hippocampus; neurogenesis; immature neuron complexity

Received: December 21, $2017 \quad$ Accepted: July 31, $2018 \quad$ Published: August 31, 2018

Copyright: Ferreiro et al. This is an open-access article distributed under the terms of the Creative Commons Attribution License 3.0 (CC BY 3.0), which permits unrestricted use, distribution, and reproduction in any medium, provided the original author and source are credited.

\section{ABSTRACT}

Brain cognitive reserve refers to the ability of the brain to manage different challenges that arise throughout life, making it resilient to neuropathology. Hippocampal adult neurogenesis has been considered to be a relevant contributor for brain cognitive reserve and brain plasticity. Coriolus versicolor (CV), a common healthful mushroom, has been receiving increasing attention by its antitumoral, antiinflammatory, antioxidant, antibacterial, and immunomodulatory properties, including in the hippocampus. Herein, we evaluated whether CV biomass oral administration for 2.5 months enhances hippocampal neurogenic reserve under normal/physiological conditions, by quantifying hippocampal dentate gyrus (DG) granular cell layer (GCL) and subgranular zone (SGZ) volumes, proliferation, number and dendritic complexity features of hippocampal newly-generated neurons. We also analyzed $\beta$-catenin levels in DG newly-generated immature neurons, because it plays a major role in neurogenesis. Although no differences were observed in the volume of GCL and SGZ layers, in proliferation and in the number of newly-generated neurons of controls and CV-administered mice, we found that CV administration promotes a significant increase in dendritic length and branching and total dendritic volume of immature neurons, suggesting a positive effect of oral CV administration in the hippocampal neurogenic reserve. We also observed that $\beta$-catenin levels are increased both in the nucleus and cytoplasm of DG immature neurons, suggesting that Wnt/ $\beta$-catenin signalling may play an important role in the CV positive effect on the differentiation 


\section{of these cells. These data unveil a so far unexplored neurogenic potential of CV supplementation, which emerges as a possible preventive strategy for different neurological conditions.}

\section{INTRODUCTION}

The brain must cope with different challenges throughout life. The capacity of the brain to respond to these insults may define the difference between undergoing healthy aging or developing a neurological disease. Brain cognitive reserve reflects the brain capacity to preserve normal function [1]. Several factors modulate the cognitive reserve, namely nutrition, stress, exercise and environmental enrichment. Albeit the difficulty to evaluate the cognitive reserve status, different parameters have been used to assess brain function potential, such as brain volume, neuronal number and dendritic complexity [1]. Particularly, hippocampal adult neurogenesis has been pointed out as a putative contributor to the cognitive reserve [2]. The production of adult hippocampal neurons requires the continuous division of neural stem/progenitor cells, differentiation of newly-generated granule cells and their integration into the pre-existing circuits under specified extracellular conditions [3]. This integration into the hippocampal circuitry relies on newly-formed dendritic branches of pre-matured neurons that reach the dentate gyrus (DG) molecular layer (ML), where they receive inputs from the entorhinal cortex (EC) lateral (LPP) and medial (MPP) perforant path, forming novel synaptic connections [4]. These cells are able to project their axons to the Cornu Ammonis 3 (CA3), further establishing the hippocampal circuitry. Besides this tight communication with EC fibers, these newly-generated neurons also receive inputs from DG mature neurons [3]. Although physiological formation of newly-generated neurons tends to decrease with age in a slow pace, addition of a small number of these cells is critical for DG-dependent memory processing due to their enhanced excitability [3]. Adult neurogenesis, in particular the maturation of newly-generated neurons, is regulated by the action of epigenetic mechanisms, including DNA methylation, histone modification and transcriptional feedback loop (reviewed in [5]). Wnt/ $\beta$ catenin signalling is another major player in neurogenesis $[6,7]$. In this respect, $\mathrm{Wnt} / \beta$-catenin signalling was previously shown to be involved in the maturation of the newly-generated dendritic tree $[7,8]$. In turn, epigenetic mechanisms and $\mathrm{Wnt} / \beta$-catenin pathway are influenced by environmental factors, including dietary exposures and nutritional status $[9,10]$. Discovering dietary tools that promote neurogenesis, namely the efficient integration of newly-generated neurons, may prove to be essential for the maintenance of the brain cognitive reserve and provide the brain with means to cope with several insults.

Coriolus versicolor $(\mathrm{CV})$ is a common healthful mushroom that has been used for thousands of years in traditional oriental therapies [11]. Recent studies suggested that this mushroom is endowed with antitumoral, anti-inflammatory, antioxidant, antibacterial and immunomodulatory properties [12-14]. CV can be presented in the form of biomass or extract. Unlike the extract form, originated from concentrated extracts of the fruiting bodies, the biomass comprises mycelia and primordia, which renders it more resistant to proteolytic enzymes of the digestive tract [15]. Due to its enrichment in enzymes with immuneenhancing activity and other substances including $\beta$-glucans, which are likely to act in a synergistic manner, CV biomass is seemingly more effective in promoting the detoxification of reactive oxygen species (ROS), thus preventing oxidative stress, when compared with CV extracts [16]. Recently, $\mathrm{CV}$ biomass administration was shown to promote an upregulation of lipoxin A4 (an anti-inflammatory mediator) and an increase in the levels of redox-sensitive proteins involved in the cellular stress response, such as Hsp72, heme oxygenase- 1 and thioredoxin, in several brain areas, namely the cortex and the hippocampus [17]. Moreover, $\mathrm{CV}$ polysaccharide administration was shown to improve spatial memory in a mouse model of Alzheimer's disease (AD), by increasing the antioxidant activity, through an increase in superoxide dismutase (SOD) and catalase (CAT) mRNA levels, and inhibition of pro-inflammatory cytokines, namely interleukin-1 $\beta$ (IL-1 $\beta$ ), interleukin-6 (IL-6) and tumor necrosis factor-alpha (TNF- $\alpha$ ) [18].

Although a substantial number of reports highlight the beneficial potential of $\mathrm{CV}$ administration, much has yet to be performed to uncover its positive effects on hippocampal neurogenic reserve, as well as cellular and molecular mechanisms involved in these processes. Therefore, the present study was conducted to evaluate whether $\mathrm{CV}$ biomass oral administration promotes hippocampal neurogenic reserve under normal/ physiological conditions. To achieve this purpose, we quantified hippocampal DG and subgranular zone (SGZ) volume and the number of hippocampal newly-generated neurons, and analyzed the differentiation features of these immature neurons in CV-administered wild-type mice.

Overall, our data strongly suggest that $\mathrm{CV}$ dietary supplementation promotes hippocampal neurogenic reserve through an increase in dendritic arborization of newly-generated neurons, which is accompanied by an increment in cytoplasmatic and nuclear $\beta$-catenin levels. This increase in dendritic complexity may translate into enhanced cognitive reserve.

\section{RESULTS}

To evaluate whether Coriolus versicolor (CV) biomass promotes hippocampal neurogenic reserve, 2.5 month-old mice were administered with $200 \mathrm{mg} / \mathrm{kg}$ every 
day for 2.5 months. During CV administration, animals were monitored in terms of body weight and food and water consumption (Table 1). No significant differences were registered either on the percentage of weight gain, or on total body weight between the two experimental conditions. Indeed, food consumption remained equivalent between controls and $\mathrm{CV}$-administered mice, but the latter mice consumed less water than the controls.

As a measure of the effect of $\mathrm{CV}$ administration on the hippocampal neurogenic reserve, we quantified the volume of granular cell layer (GCL) and subgranular zone (SGZ) of the hippocampal dentate gyrus (DG), proliferation, number of hippocampal newly-generated neurons and analyzed the differentiation features of these immature neurons from saline- and $\mathrm{CV}$-administered mice. Levels of $\beta$-catenin were also measured in DG newlygenerated immature neurons.

\section{GCL and SGZ volumes, proliferation and number of newly-generated neurons remain unchanged after $\mathrm{CV}$ administration}

First, we analyzed the effect of 2.5 months of CV administration in the volume of GCL and SGZ layers of the hippocampal DG (Figure 1A). No differences in the volume of the GCL (Figure 1B, $i$ ) and SGZ (Figure 1B, ii) were observed between controls and CV-administered 5 month-old mice. Proliferation was further studied by counting the number of cell expressing Ki67, a known marker of proliferation that is expressed in all phases of the active cell cycle of proliferating cells (G1, S, G2 and M) [19] (Figure 1C and 1D). We specifically analyzed the proliferation associated to the late stage of neurogenesis. Therefore, cells co-expressing Ki67 and doublecortin [DCX; a microtubule-associated protein expressed in early neuroblasts and new neurons and involved in neuronal migration and differentiation [20-22]] were counted (Figure 1C and 1D). Total cell number was mathematically estimated relatively to the entire hemisphere (as described in 'Materials and Methods' section). Since immature neurons correspond to the postmitotic phase of DCX-positive cells, the majority of DCX \& Ki67-positive cells can be considered as proliferating neuroblasts [23]. No differences were observed neither in the general proliferation (Ki67positive cells; Figure 1D, $i$ ) nor in the proliferation of neuroblasts (Ki67- and DCX-positive cells, Figure 1D, ii) between control and CV-supplemented mice. Moreover, and concordantly with proliferation data, both the number of GCL immature neurons (Figure $1 \mathrm{E}$ and $1 \mathrm{~F}, i$ ), and the nucleus area of these cells (Figure 1E and Figure 1F, ii) were similar between controls and $\mathrm{CV}$-administered mice.

\section{CV administration promotes dendritic branching of immature neurons}

To assess dendritic complexity, immature neurons were stained for DCX. A requirement for the successful synaptic integration and subsequent functionality of newly-generated neurons is the sprouting and extension of dendrites into the ML of the dentate gyrus (DG), where the synaptic connections are formed [24]. Thus, measurement of dendritic complexity is an indicator of neuronal differentiation in hippocampal adult neurogenesis. To analyze the complexity of newlygenerated neurons, DCX cells with morphology of immature neurons (EF-DCX cells) were 3D reconstructed and analyzed by Sholl analysis [25]. Both the maturation stage and the localization of dendrites and establishment of connection in the specific layers of the ML, namely inner molecular layer (IML) and outer and medial molecular layer (O/MML), leads to distinct types of response by the immature neurons (for review [26, 27]). Therefore, EF-DCX cells with dendrites reaching or not the DG O/MML were identified, herein named as "long" or "short" immature neurons, respectively. Sholl analysis of short immature neurons revealed a positive effect of $\mathrm{CV}$ administration in the number of dendritic intersections, in the radius 50 and $60 \mu \mathrm{m}$, reflecting a slight increase in the dendritic complexity of these cells (Figure 2C). In terms of other features of complexity, $\mathrm{CV}$ did not alter the total dendritic length, number of dendritic branches, branch junctions or the number of junctions with three branches (dendrites triple points) in both the GCL and IML of short cells, when compared to control mice (Figure 2D, $i-i v$ and 2E, $i-i v$ ). Importantly, the positive alterations found in the Sholl analysis of short immature neurons from $\mathrm{CV}$-administered mice were accompanied by a significant increase in the neuronal volume of short immature neurons ( 1.6 fold), when compared to control mice (Figure 2A and 2B).

In the case of immature neurons reaching the $\mathrm{O} /$ MML, a more pronounced effect of $\mathrm{CV}$ administration was found in the Sholl analysis of the dendritic arborization, namely in radiuses 80 to $110 \mu \mathrm{m}$ (Figure 3C). The significant increase in the number of intersections in these radiuses strongly suggests a specific effect on the dendrites located at the DG IML. This was further confirmed by the observation that $\mathrm{CV}$ administration strongly contributed to the significant increase in the length and number of junctions with three branches (dendrites triple points) of dendrites located at the IML (Figure 3E, $i$ and $i i$ ). In addition, an almost statistical increase in the number of branches ( $p=0.0542)$ was found in the DG IML of CV-administered mice (Figure 3E, iii). The fact that no alterations were found in total dendritic length, number of dendritic branches, branch junctions and triple points, in both the GCL and O/MML (Figure 3D, $i-i v$ and 3F, $i-i v$ ), further shows the specific effect of $\mathrm{CV}$ administration on the long immature neurons dendrites located at the IML. Finally, a significant increase in neuronal volume ( 1.5 fold) was found in long immature neurons from $\mathrm{CV}$-administered mice, when compared to control mice (Figure 3A and 3B). 
Table 1: Effects of daily CV administration ( $200 \mathrm{mg} / \mathrm{kg}$ body weight) on animals' body weight and food and water consumption

\begin{tabular}{lcr}
\hline & Saline & CV \\
\hline Final body weight $(\mathrm{g})$ & $27.6 \pm 0.4$ & $27.0 \pm 0.4$ \\
Weight gain $(\%)$ & $8.9 \pm 2.0$ & $9.3 \pm 1.5$ \\
Food intake $(\mathrm{g})$ & $3.2 \pm 0.1$ & $3.1 \pm 0.1$ \\
Water intake $(\mathrm{mL})$ & $5.0 \pm 0.2$ & $4.1 \pm 0.2^{* * *}$ \\
\hline
\end{tabular}

a:data are expressed as mean SEM for 10 animals per group. Mann-Whitney test: ${ }^{* * *} p<0.001$ vs saline.

b:CV: Coriolus versicolor.

\section{Diet supplementation with $\mathrm{CV}$ upregulates $\beta$-catenin levels both in the nucleus and cytoplasm of DG immature neurons}

Among the different molecules found to intervene in the epigenetic regulation of adult neurogenesis, three types of regulators have been identified to interfere with the maturation and integration of newborn neurons: DNA (cytosine-5)-methyltransferases (DNMTs), Methyl-CpG binding protein $2(\mathrm{MeCP} 2)$ and histone deacetylases (HDACs) (reviewed in [5]). In line with this reasoning, we evaluated the mRNA levels of DNMT1, HDAC1 and $\mathrm{MeCP} 2$ in the hippocampal samples of control and $\mathrm{CV}$-supplemented mice. As depicted in Figure $4 \mathrm{~A}$, no significant differences were found on mRNA expression of these genes. Since the number of immature neurons accounts for a very small portion of the entire hippocampus, it is highly possible that the specific effect of $\mathrm{CV}$ administration on these epigenetic regulators from immature neurons is masked in these samples.

On the other hand, it was shown that activation of Wnt signaling in the SGZ increased adult neurogenesis, whereas its inhibition caused a reduction in proliferation and neuronal differentiation [6]. Therefore, we quantified the $\beta$-catenin levels in the nucleus and cytoplasm of the newly-generated neurons showing increased arborization, by immunohistochemistry. A clear increase in $\beta$-catenin levels was observed in both the cytoplasm (Figure $4 \mathrm{C}, i$ and $4 \mathrm{C}, i i$ ) and nucleus (Figure $4 \mathrm{C}$, iii and $i v$ ) of the immature neurons from $\mathrm{CV}$-administered mice, when compared to control mice (Figure $4 \mathrm{~B}$ and $4 \mathrm{C}$ ), suggesting that $\mathrm{CV}$ may stimulate this signalling pathway, which may in turn be responsible for the increase in maturation of newlygenerated neurons, promoted by $\mathrm{CV}$ supplementation.

\section{DISCUSSION}

The brain is constantly challenged by different insults, such as disease states, stress, injury and/or aging. In recent years, it has been hypothesized that the capacity of the brain to cope with these insults, and maintain normal function, is highly dependent on the brain cognitive reserve [28, 29]. This capacity of the brain to develop compensatory mechanisms is positively or negatively modulated by exogenous factors, such as lifestyle, exercise or nutritional factors, which can determine healthy aging or the development of age-dependent neurodegenerative diseases [30, 31]. Many authors have pointed out the relevance of cognitive reserve and lifestyle for diseases such as AD, Parkinson's disease (PD) and Huntington's disease (HD) [28, 32-34]. Brain cognitive reserve is a theoretical concept that may be indirectly measured [35]. Some brain properties directly related to brain plasticity have been suggested to be constituents of the brain cognitive reserve and, thus, indicators of its state, such as volume of brain structures, neuronal number, neuronal complexity and connectivity [28]. Importantly, hippocampal adult neurogenesis has been described to contribute to the volume of the DG, increase and maintain the number of granule cells [36], and mainly the dendritic tree of adult newly-generated neurons adapts to behavioural demands in the DG [37]. Therefore, as previously proposed, hippocampal adult neurogenesis may be considered as part of the brain cognitive reserve and reflects its state [38]. Numerous factors can shape the neurogenic process and identifying such factors, which positively modulate the production and integration of new neurons, may prove to be essential for the response of the brain to insults that may lead to neuropathology. In this study, it was demonstrated that oral supplementation with $\mathrm{CV}$ biomass promotes an increase in the arborization of the dendritic tree of hippocampal immature neurons, which is more evident in newly-generated neurons with dendrites reaching the DG O/MML. Data revealed a modest increase in the number of dendrite intersections in the Sholl analysis of immature neurons with dendrites ending in the IML from CV-administered mice, when compared to control mice. These cells may correspond to an early stage of differentiation that, with time, might give rise to cells with a similar morphology to the ones observed in immature neurons reaching the O/MML (long immature neurons). During the first week of cell development, DG newly-generated neurons extend their dendritic processes into the IML, not reaching the OML [39], with a morphology very similar to that of cells called short immature neurons. During the following 
week, these cells extend their dendritic branching and reach the O/MML [40]. After this period, and in the next two weeks, these cells may develop a complex dendritic arbor, with the development of spines and the first glutamatergic inputs, reaching the maximum level of maturity [40]. This level of differentiation will then allow the establishment of contacts with the existing entorhinal cortex (EC) [39]. Both Sholl analysis and complexity parameters indicate that $\mathrm{CV}$ supplementation induces an increase in the complexity of long immature neurons dendrites residing in the IML, including their length. Neurons in the DG ML

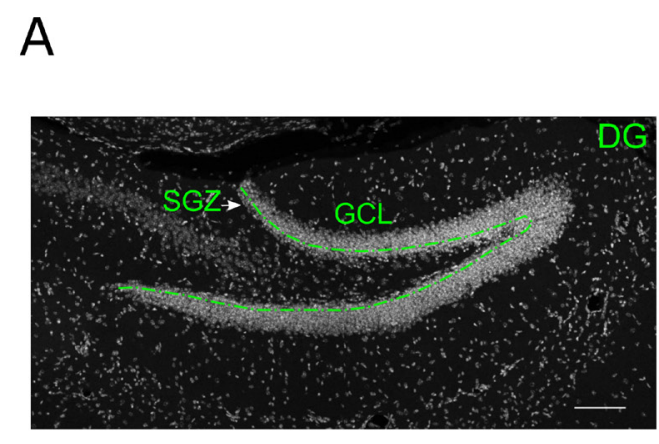

$\mathrm{B}_{i}$
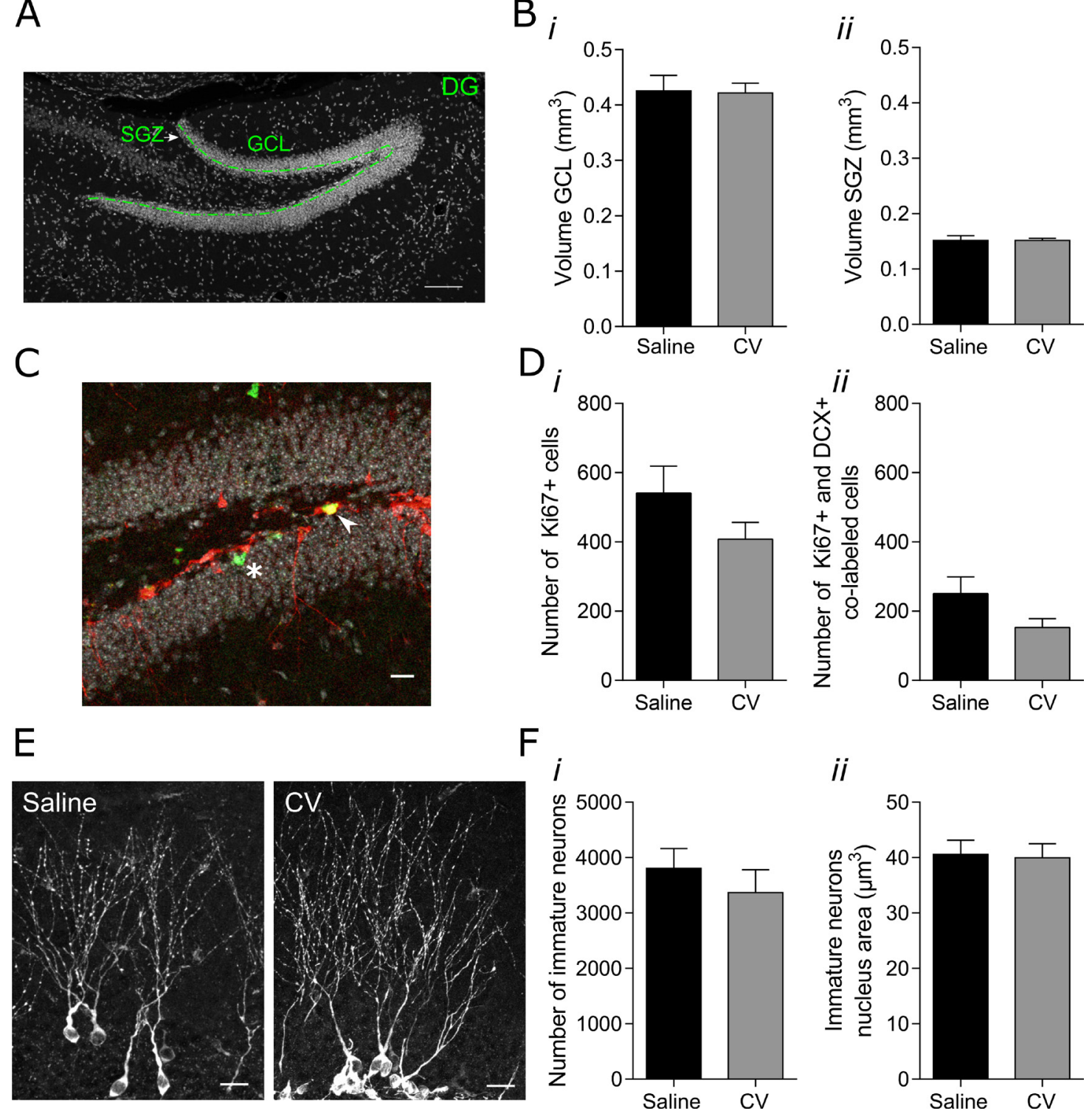

\section{$\mathrm{F}$}
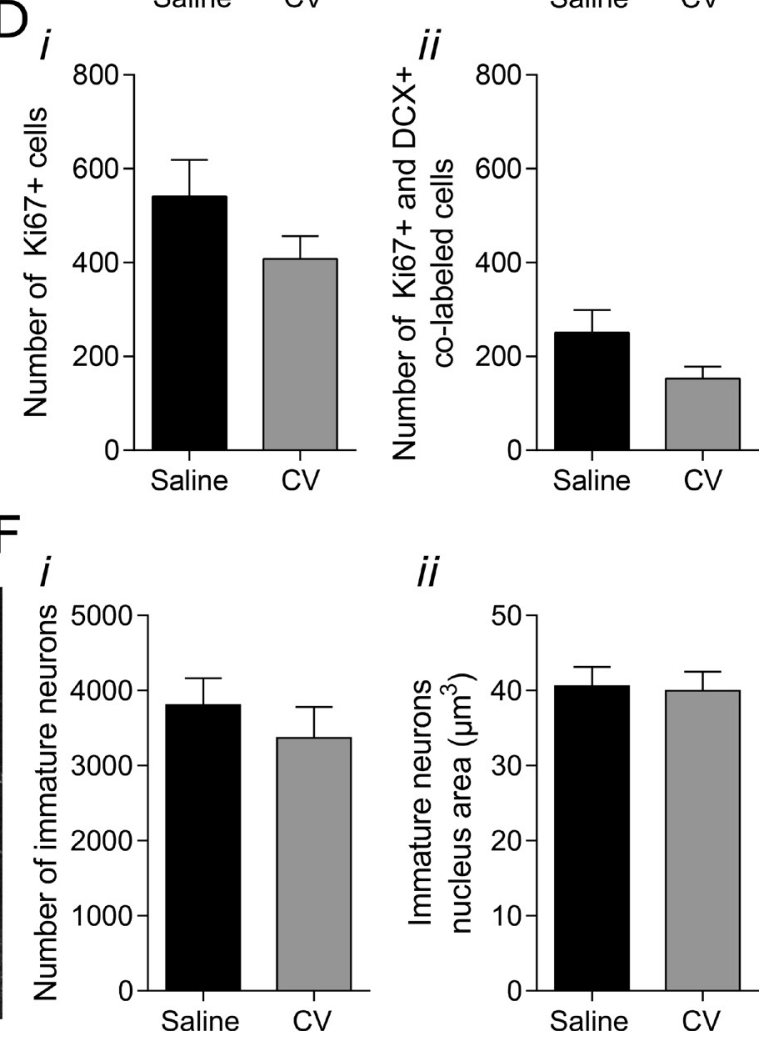

Figure 1: Effect of CV administration on the volumes of the GCL and SGZ of the hippocampal DG, on proliferation of DCX-positive cells and on the number and nucleus area of immature neurons in the DG of mouse hippocampus. (A) Confocal microscope image showing the SGZ and GCL of the hippocampal DG. Cell nuclei were stained with Hoechst 33342 (in grey). Green line represents the separation between the SGZ and GCL. Scale bar: $50 \mu \mathrm{m}$. (B) Volumes of GCL ( $i$ ) and SGZ (ii) (unpaired $t$ test or Mann Whitney test). (C) Confocal microscope image showing Ki67- and DCX-positive cells. The arrow indicates a cell expressing both Ki67, a proliferation marker (in green) and DCX (in red), demonstrating a proliferating neuroblast. The asterisk indicates a cell expressing Ki67 and negative for DCX, corresponding to a different type of cell in proliferation. Scale bar: $20 \mu \mathrm{m}$. (D) Quantification of the number of Ki67-positive cells ( $i$ ) and Ki67-positive cells co-labeled with DCX-positive cells in the GCL of the hippocampal DG (ii) (Mann-Whitney test). (E) Confocal microscope images showing immature neurons in the hippocampal DG. Immature neurons were stained with DCX antibody (in grey). Scale bar: $20 \mu \mathrm{m}$. (F) Quantification of the number of immature neurons in the GCL (i) and immature neurons nucleus area (ii) (unpaired $t$-test). Data are expressed as mean \pm SEM. of 9-10 mice per group for GCL and SGZ volumes, 5 mice for the number of Ki67-positive cells and Ki67-positive and DCX-positive co-labeled cells, or 5-6 mice for the number of immature neurons and immature neurons nucleus area. 
can receive inputs from different afferent sources. In the case of $\mathrm{O} / \mathrm{MML}$ neurons they establish contacts with fibers from the lateral or medial EC (innervating the OML, respectively) [27]. Dendrites located at the IML in turn receive inputs mainly from the mossy cell axons [27]. A possible role for mossy cells are their contribution for pattern separation, a process involving the crossing of information coming from the EC [27]. Since the role of mossy cells on hippocampal neurogenesis and its contribution for functionality is very limited, we can hypothesize that immature neurons from $\mathrm{CV}$-administered mice, with more dendrites at the IML, may establish contacts with these circuits and potentiate the pattern separation process.
A
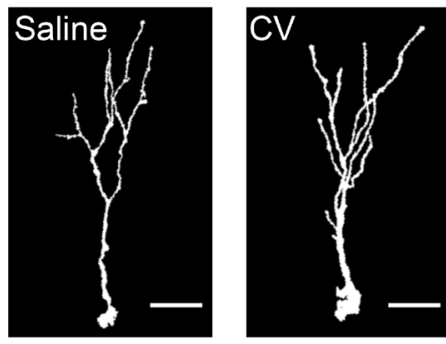

C

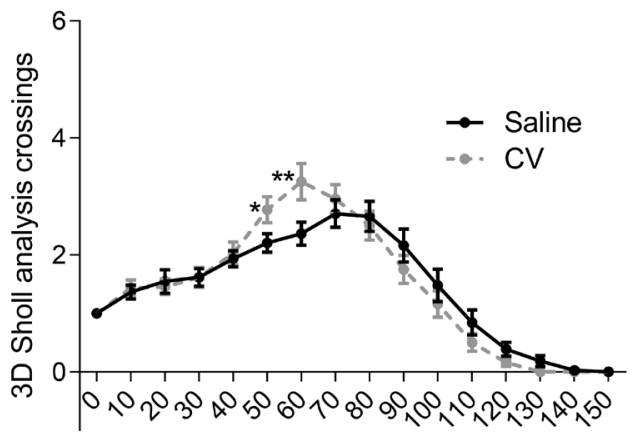

B

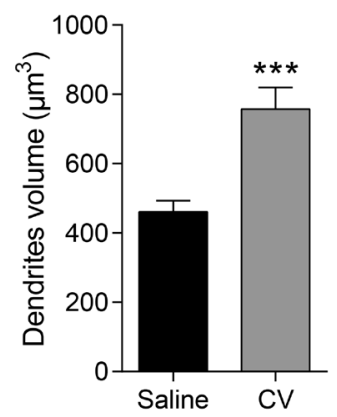

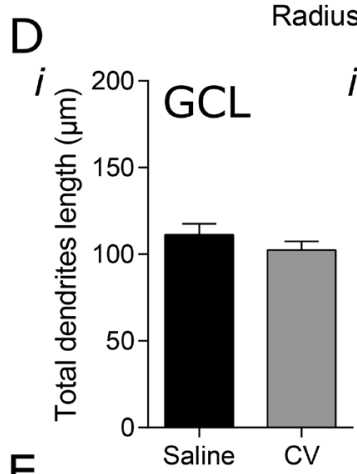

Radius ( $\mu \mathrm{m}$ from soma)

$\mathrm{E}$
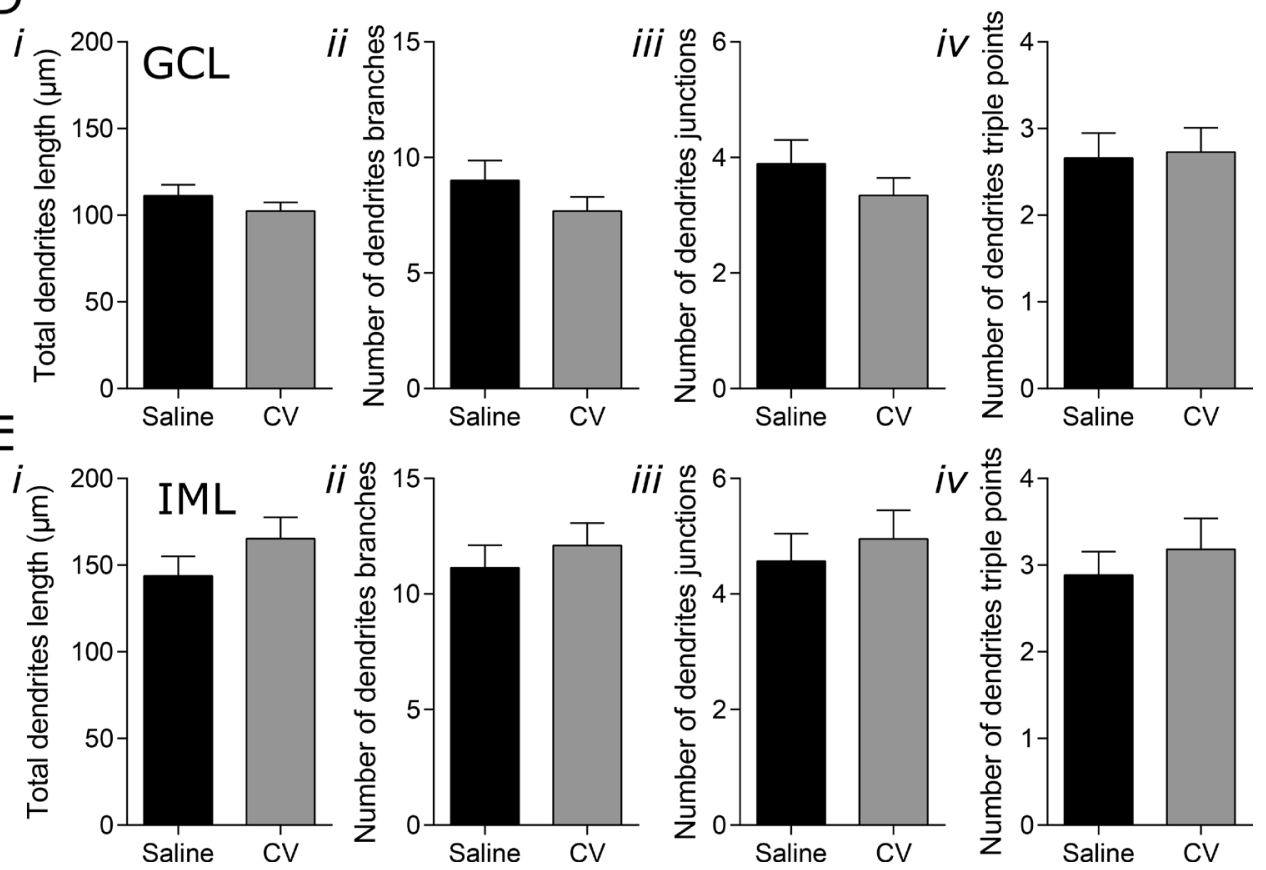

Figure 2: Effect of CV on the morphology of DG short immature neurons of mouse hippocampus. (A) Three dimensional (3D) reconstructions of short immature neurons (EF DCX-positive cells that do not reach the O/MML). Scale bar: $20 \mu \mathrm{m}$. (B) Dendrites volume (Mann-Whitney test: ${ }^{* * *} p<0.001$ vs saline). (C) 3D Sholl analysis (one-way ANOVA with repeated measures and Bonferroni post hoc test: ${ }^{*} p<0.05 ;{ }^{* *} p<0.01$ vs saline). Dendrites length $(i)$, number of neuronal branches (ii), number of neuronal junctions (iii) and number of triple points (iv) in the GCL (D) or in the IML (E) of the hippocampal DG. Data are expressed as mean \pm SEM of 44 cells per group. 

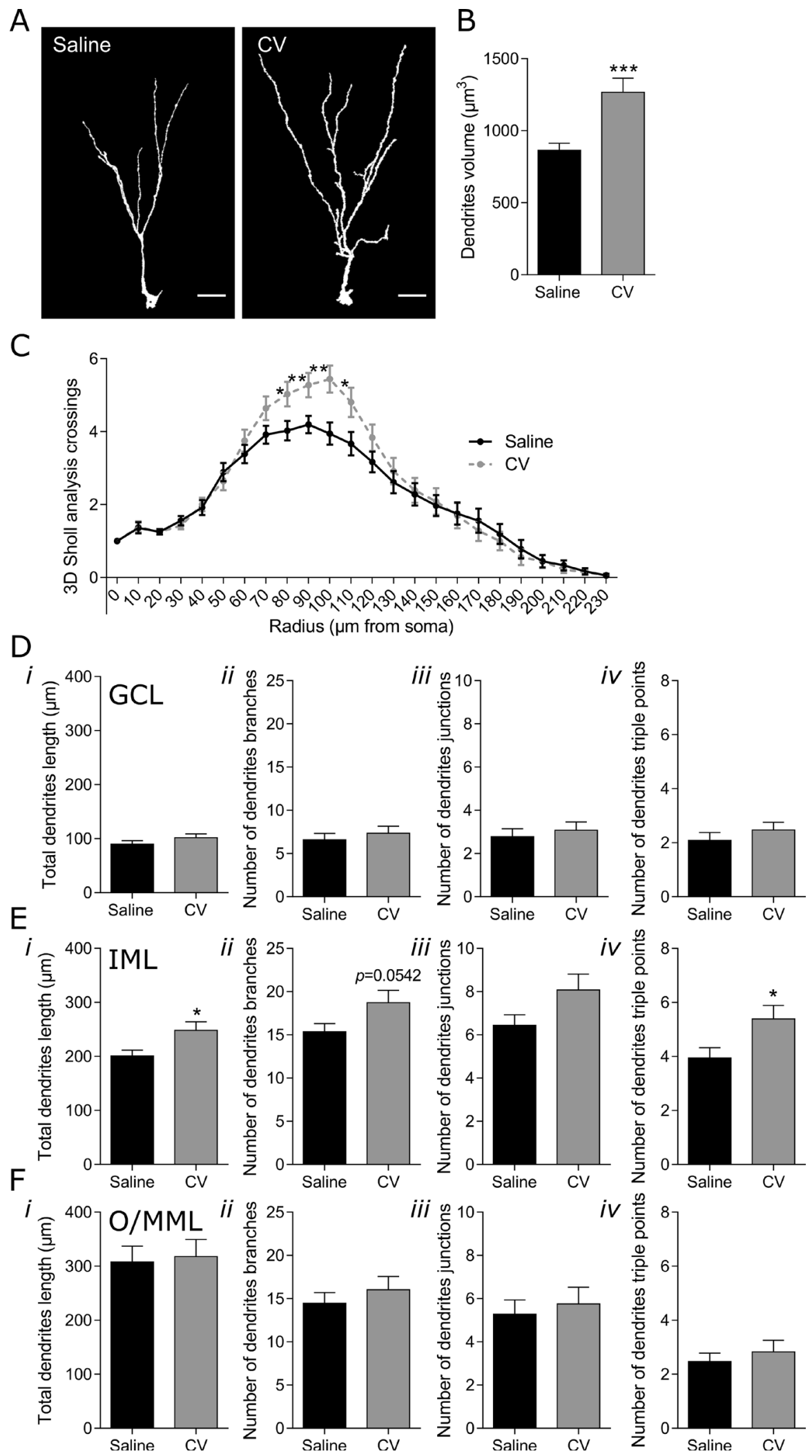

Figure 3: Effect of CV on the morphology of DG long immature neurons of the mouse hippocampus. (A) Three dimensional (3D) reconstructions of long immature neurons (EF DCX-positive cells that reach the O/MML. Scale bar: $20 \mu \mathrm{m}$. (B) Dendrites volume (unpaired $t$ test: ${ }^{* * *} p<0.001$ vs saline). (C) 3D Sholl analysis (one-way ANOVA with repeated measures and Bonferroni post hoc test: ${ }^{*} p<$ $0.05,{ }^{* *} p<0.01$ vs saline). Dendrites length $(i)$, number of neuronal branches (ii), number of neuronal junctions (iii) and number of triple points $(i v)$ in the GCL (D), IML (E) and O/MML (F) of the hippocampal DG (unpaired $t$ test or Mann-Whitney test: ${ }^{*} p<0.05 v s$ saline). Data are expressed as mean \pm SEM of 36 cells per group. 

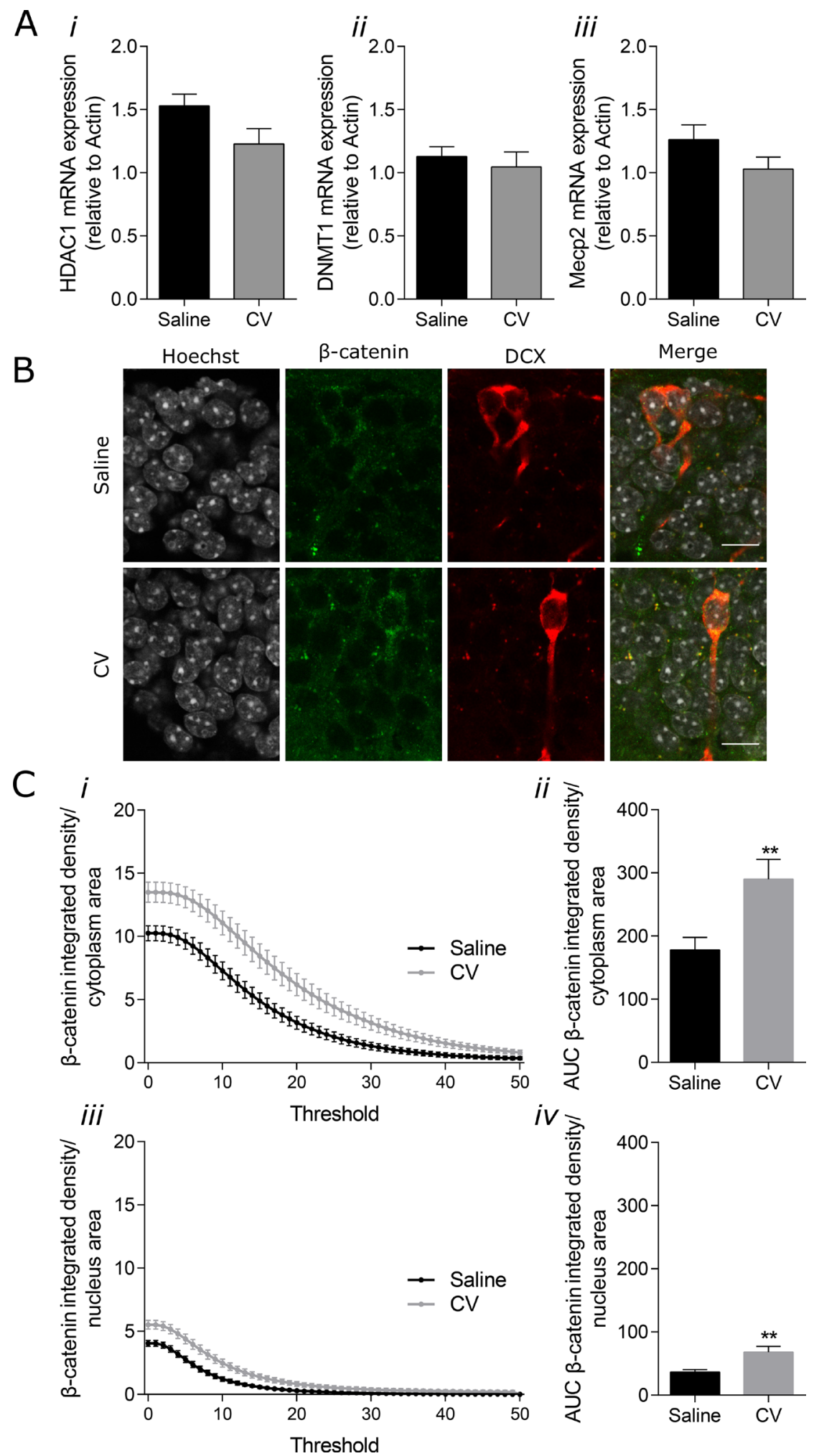

Figure 4: Effect of CV on mRNA expression of HDAC1, DNMT1 and Mecp2 in the mouse hippocampus and on $\boldsymbol{\beta}$-catenin levels in the cytoplasm and nucleus of DG immature neurons. (A) mRNA expression levels of HDAC1 ( $i$ ), DNMT1 (ii) and Mecp2 (iii) in the mouse hippocampus. (B) Confocal microscope images showing $\beta$-catenin staining in immature neurons in the hippocampal DG (nuclei in grey, DCX in red and $\beta$-catenin in green). Merge images show the presence of $\beta$-catenin in the nucleus and cytoplasm of immature neuron. Scale bar $20 \mu \mathrm{m}$. (C) $\beta$-catenin integrated density per area (from threshold 1-50) (i and iii) and area under the curve (AUC) ( $i i$ and $i v$ ) in the cytoplasm ( $i$ and $i i$ ) and nucleus (iii and $i v$ ) of immature neurons from the DG (Mann-Whitney test: ${ }^{* *} p<0.01$ vs saline). Data are expressed as mean \pm SEM of 10 mice per group for mRNA expression, and 43 cells from 6 mice $p e r$ group for $\beta$-catenin levels quantification. 
Although we did not observe any alteration in GCL and SGZ volume, as well as in proliferation of neuroblasts and number of immature neurons, parameters used to measure hippocampal neurogenic reserve, it is possible to infer that a more prolonged treatment and/or an increase in the dose of CV supplementation would result in an increase of both number and volume of neuronal cells. In view of the fact that the available literature is very sparse or inexistent regarding the effect of CV administration on proliferation and neuronal survival, additional experiments addressing this issue are warranted. Nonetheless, given the potential role of adult hippocampal neurogenesis, especially the integration of new neurons, for pattern separation and spatial learning [38, 41], an extended dendritic arborization of newly-generated neurons is expected to enhance the probability of integration into the local hippocampal circuitry. Therefore, the increased dendritic complexity seen herein is suggestive that oral $\mathrm{CV}$ administration has a positive effect in the hippocampal neurogenic reserve, which may prevent cognitive impairment upon deleterious events that accompany aging and neurodegenerative diseases. However, future studies will be necessary to address these issues. Interestingly, the positive effect exerted by $\mathrm{CV}$ administration on dendritic complexity is similar to that obtained with environmental enrichment (EE) [42, 43]. In fact, EE has been widely described to promote hippocampal neurogenesis and to enhance cognition in models of disease, such as AD [44].

Despite the potential health effects of $\mathrm{CV}$, its molecular targets are still poorly known. Numerous signals regulate hippocampal neurogenesis in its distinct stages, both by intrinsic factors, namely intracellular signalling pathways, microenvironment or cell to cell interaction; and extrinsic factors, such as diet (for review [26]). One of the signalling pathway that plays an important role in the differentiation of neuroblasts into mature neurons is the $\mathrm{Wnt} / \beta$-catenin signalling pathway [7]. In the canonical Wnt/ $\beta$-catenin pathway, $\beta$-catenin cytoplasmic levels are dynamically regulated by a complex composed of adenomatous polyposis coli (APC), Axin, glycogen

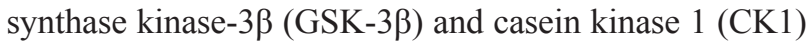
that phosphorylates $\beta$-catenin, leading to its ubiquitination and proteasomal degradation $[45,46]$. When Wnt is present and interacts with Frizzled (Fzd) family receptors, this complex is inhibited, allowing the increase in cytoplasmic $\beta$-catenin levels and its translocation to the nucleus [45]. In the nucleus, $\beta$-catenin interacts with $\mathrm{T}$ cell factor/lymphoid enhancer factor-1 (TCF/Lef1) and activates the TCF/Lef1 transcription complex, promoting cellular differentiation $[45,47]$. Interestingly, CV supplementation leads to an increase of both cytoplasmic and nuclear levels of $\beta$-catenin in immature neurons from hippocampal DG, suggesting that this protein may be a key molecule responsible for the increase in dendritic complexity in these cells. To our knowledge, this is the first time that CV supplementation has been described to alter the Wnt/ $\beta$-catenin signalling pathway, by increasing $\beta$-catenin levels. On the other hand, although epigenetic mechanisms are amenable to modulation by diet [9], CV supplementation does not seem to change the hippocampal expression of genes that are epigenetic regulators of adult neurogenesis. However, since the number of immature neurons accounts for a very small portion of the entire hippocampus, it is highly possible that any specific effect of CV administration on these epigenetic regulators in immature neurons might be masked in these samples representing total hippocampus. In pathological situations, it is possible that $\mathrm{CV}$ also exerts a protective effect on hippocampal adult neurogenesis through its action as an antioxidant. In fact, it was suggested that an acetone $\mathrm{CV}$ extract was endowed with antioxidant properties [48]. These authors further demonstrated that this extract was enriched in furfural, furfuryl alcohol, 2-methoxy-4vinylphenol and 2,6-dimetoxy-4-vinylphenol. Furfural and furfuryl alcohol are non-phenolic compounds whereas 2-methoxy-4-vinylphenol and 2,6-dimetoxy-4-vinylphenol are phenolic compounds. Additionally, CV contains immunonutrients proteoglycans (eg. polysaccharopeptide Krestin - PSK), which have antioxidant properties [16]. Although the impact of these compounds was never tested in neurogenesis, we may argue that the positive effect of $\mathrm{CV}$ seen herein may be the result of the synergistic action of $\beta$-glucans, proteoglycans, furfurals and the phenolic compounds 2-methoxy-4-vinylphenol and 2,6-dimetoxy4-vinylphenol. Moreover, as previously mentioned, CV administration can upregulate lipoxin A4, which in turn promotes an increase in redox-sensitive neuroprotective proteins involved in cellular stress response, such as Hsp72, heme oxygenase-1 and thioredoxin [17]. Although slight production of ROS may occur along the neurogenic process and is therefore physiological [49], prolonged oxidative stress, which typically occurs in aging and neurodegenerative diseases, may contribute for neurogenesis impairment [50].

In conclusion, our data demonstrate that supplementation with $\mathrm{CV}$ biomass promotes the increase in the levels of $\beta$-catenin in the nucleus and cytoplasm of hippocampal newly-generated neurons. It is tempting to argue that this may contribute to the increase in dendritic arborization, and, therefore, to the reinforcement of the neurogenic cognitive reserve. This improvement may thus promote the brain capacity to cope with insults, favouring normal brain function.

\section{MATERIALS AND METHODS}

\section{Animals and ethics statement}

Wild-type mice (C57BL/6 × 129 background) were bred and maintained at CNC-Faculty of Medicine animal house (license $n^{\circ} 520.000 .000 .2006$, from the Portuguese animal welfare authorities). Two and half month-old male mice were randomly divided in 2 experimental groups 
( $n=10$ per group): i) Saline-administered animals and ii) CV-administered animals $(200 \mathrm{mg} / \mathrm{kg}$ body weight, suspended in saline (as in [11]). Mice were grouped in cages of 4-6 animals and kept in the same room, under standard laboratory conditions $\left(21 \pm 2^{\circ} \mathrm{C}, 12 \mathrm{~h}\right.$ light/dark cycle starting at 07:00 am, ad libitum access to food (\# 4RF21A, Mucedola, Milanese, Italy) and water. CV biomass (supplied by Mycology Research Laboratories Ltd, Luton, UK) was micronized to allow its administration by oral gavage with flexible cannulas (22 Gauge, 25 mm length; B. Braun, Bethlehem, USA). Saline vehicle was administered to control mice. The administration of $\mathrm{CV}$ or saline was performed every day for 2.5 months. During this period, liquid consumption was monitored every two days, while food consumption and animal weight were monitored once a week. All procedures were performed to minimize exposure to stress and suffering, in accordance with the approved animal welfare guidelines of the institutional animal house (local welfare approval: ORBEA_140_2016/15072016) and European legislation (European directive 2010/63/EU).

\section{Preparation of Coriolus versicolor biomass low size particles}

Before size reduction procedures, the original $\mathrm{CV}$ powder was analyzed by Attenuated Total Reflectance Infrared Spectroscopy (ATR-FTIR) and its particle size distribution was determined by laser diffraction (data not shown). Then, the powder was submitted to manual pulverization with a mortar, in order to reduce particle size. After pulverization, sieving was performed with a Retsch AS 200 sieve shaker. With this procedure four different granulometry (particle size ranges) were obtained: 1) $>355 \mu \mathrm{m}$; 2) $355 \leq$ particle size $\leq 125 \mu \mathrm{m}$; 3) $125<$ particle size $\leq 90 \mu \mathrm{m}$ and 4) $<90 \mu \mathrm{m}$. After sieving, a sample of each granulometry was analyzed by ATR-FTIR and laser diffraction to determine the particle size distribution and the results were compared with the original powder. ATR-FTIR results showed that all of them shared the same structural composition of the original powder, and the laser diffraction analysis confirmed the reduction in mean and median particle size that was achieved with this procedure (data not shown). By using the fraction with the lowest granulometry $(<90 \mu \mathrm{m})$, it was possible to prepare a suspension that did not clog the oral gavage cannulas used to administer the biomass to the animals.

\section{Immunofluorescence staining}

Mice were deeply anesthetized with sodium pentobarbital (70 $\mathrm{mg} / \mathrm{kg}$ i.p.) and perfused intracardially with $0.9 \% \mathrm{NaCl}$, for $4 \mathrm{~min}$. Brain were immediately dissected and the left hemisphere postfixed with $4 \%$ paraformaldehyde in phosphate buffered saline (PBS; containing in mM: 137 $\mathrm{NaCl}, 2.7 \mathrm{KCl}, 1.8 \mathrm{KH}_{2} \mathrm{PO}_{4}, 10 \mathrm{Na}_{2} \mathrm{HPO}_{4} .2 \mathrm{H}_{2} \mathrm{O}, \mathrm{pH} 7.4$ ), for $24 \mathrm{~h}$ at $4^{\circ} \mathrm{C}$. Hemispheres were rinsed twice with $\mathrm{PBS}$ and cryoprotected with $30 \% \mathrm{w} / \mathrm{v}$ sucrose in PBS, at $4^{\circ} \mathrm{C}$, until complete submersion. Cryoprotected hemispheres were snap frozen, kept at $-80^{\circ} \mathrm{C}$, until sectioning. Coronal slices with $40 \mu \mathrm{m}$ were obtained using a cryostat-microtome (CM3050S; Leica, Mannheim, Germany) and collected in six series. Slices were then stored at $-20^{\circ} \mathrm{C}$ in anti-freeze solution [30\% glycerol (v/v) and 30\% polyethylene glycol $(\mathrm{v} / \mathrm{v})$ in $0.1 \mathrm{M}$ phosphate buffer, $\mathrm{pH} 7.4]$.

Serial slices were used and rinsed overnight (O.N.) at $4^{\circ} \mathrm{C}$ and then $3 \times 10 \mathrm{~min}$ at room temperature (RT) with PBS. Slices were blocked with blocking solution $[3 \%$ bovine serum albumin (BSA, w/v) and $1 \%$ Triton $\mathrm{X}-100$ in PBS], for $1 \mathrm{~h}$ at RT. Sections were then incubated with primary antibodies [for triple DCX/ postsynaptic density protein 95 (PSD95)/Ki67 staining: goat anti-DCX (1:500; Clone C-18, Sc-8066, Santa Cruz Biotechnologies), mouse anti-PSD95 (1:2,000; clone K28/43, \#MABN68, Merck Millipore) and rabbit antiKi67 (1:2,000; ab16667, Abcam); for double DCX/ $\beta$ catenin staining: goat anti-DCX (1:500; Clone C-18, Sc8066, Santa Cruz Biotechnologies) and goat anti- $\beta$-catenin (1: 500; ab32572, Abcam)] prepared in blocking solution for $72 \mathrm{~h}$, at $4^{\circ} \mathrm{C}$. Sections were rinsed $3 \times 10 \mathrm{~min}$ with PBS and incubated for $2 \mathrm{~h}$ at RT with the appropriate secondary antibodies [Alexa Fluor ${ }^{\circledR} 568$ donkey anti-goat IgG (\# A-21082; Thermo Fisher Scientific), Alexa Fluor ${ }^{\circledR}$ 488 donkey anti-mouse IgG (\# A-21202; Thermo Fisher Scientific), Alexa Fluor ${ }^{\circledR} 647$ donkey anti-rabbit IgG (\#A31573; Thermo Fisher Scientific) and Alexa Fluor ${ }^{\circledR} 488$ donkey anti-rabbit IgG (\#A-21206) at a dilution of 1:1000] prepared in PBS supplemented with Hoechst 33342 $(0.2 \mu \mathrm{g} / \mathrm{ml}$; \# H1399, Thermofisher Scientific, Waltham, MA USA). Sections were finally rinsed $3 \times 10 \mathrm{~min}$ with PBS and mounted with anti-fading medium (Fluoroshield Mounting Medium, \# ab104135, Abcam).

\section{Volume and cell number quantifications}

GCL and SGZ areas (from bregma $-4.04 \mathrm{~mm}$ to bregma $-0.94 \mathrm{~mm}$ ) [51] were measured using confocal tile images of the Hoechst 33342 staining in the DG, obtained with an inverted Zeiss LSM 710 confocal microscope, equipped with a Plan-Apochromat $20 \times / 0.8$ NA objective and a $0.7 \times$ digital zoom. Consecutive slices distanced $480 \mu \mathrm{m}$ were used for this evaluation. SGZ and GCL areas were measured using Fiji software (https://fiji.sc/Fiji) [52]. A line was drawn in the inner limit of the GCL and each side of the line was thickened $12.5 \mu \mathrm{m}$ to define the SGZ. The estimation of the entire GCL and SGZ volumes in the left hemisphere were obtained by calculating the sum of the area of all the consecutive pair of measured sections. To this end, section areas were ordered from rostral to caudal and volumes were calculated applying the mathematical formula $\mathrm{V}=\pi \times \mathrm{h} \times\left(\mathrm{R}^{2}+\mathrm{r}^{2}+\mathrm{R} \times \mathrm{r}\right) / 3(\mathrm{~V}$ for volume, $\mathrm{h}$ for the distance between the two slices, $\mathrm{r}$ for the radius of the first slice (slice area) and $\mathrm{R}$ for the radius of the second slice). The volumes of the rostral end of the 
GCL and SGZ were obtained by estimating the radius of the most rostral section assuming the linear distribution of the area of the last 2 rostral sections.

The total number of immature neurons was estimated by counting EF (post mitotic and almost mature) DCX-positive cell bodies (DCX-cells with branching in the GCL and ML) in the GCL of consecutive slices distanced $480 \mu \mathrm{m}$, representing the entire DG (from bregma $-4.04 \mathrm{~mm}$ to bregma $-0.94 \mathrm{~mm}$ ) [51]. For this purpose, confocal stack and tile images were obtained with an inverted Zeiss LSM 710 confocal microscope, equipped with a Plan-Apochromat $20 \times / 0.8$ NA objective and a $0.7 \times$ digital zoom. Total number of immature neurons was estimated by applying the Abercrombie formula [53]. The same method was applied to estimate the total number of Ki67-positive (corresponding to all cells in proliferation in the GCL) and Ki67-positive and DCX-positive co-labelled cells in the GCL of the left hemisphere (corresponding to neuroblasts in proliferation).

\section{Analysis of dendritic morphology}

To analyze the dendritic morphology of immature neurons, confocal stack images were obtained with an inverted Zeiss LSM 710 confocal microscope, equipped with a Plan-ApoChromat $40 \times / 1.4$ NA oil-immersion objective and a $0.7 \times$ digital zoom. Three dimensional (3D) reconstruction was performed using the Simple neurite tracer plugin [54] working on the image processing package Fiji [52]. Immature neurons were grouped in two cell types: i) short (EF-DCX cells that do not reach the $\mathrm{O} / \mathrm{MML}$; ii) long (EF-DCX cells that reach the O/MML). Cell type identification was based on the identification of dendrites localization in the IML and O/MML, having PSD95 staining as a reference. 3D Sholl analysis ImageJ plugin (https://fiji.sc/Sholl_Analysis) was used to quantify the number of intersections between dendrites and the surface of spheres with a radius increment of 10 $\mu \mathrm{m}$. Dendrite length and complexity was analyzed with the imageJ plugins Skeletonize3D (https://imagej.net/ Skeletonize3D) and AnalyzeSkeleton (https://imagej.net/ AnalyzeSkeleton).

\section{RNA extraction, reverse transcription and quantitative real time PCR}

The RNA content of mouse right hippocampi was extracted using Purezol ${ }^{\mathrm{TM}}$ (Bio-Rad, Hercules, CA, USA) reagent as described by the manufacturer's, and quantified using Nanodrop spectrophotometer. Reverse transcription was performed on each RNA sample (500 ng) using the iScript cDNA synthesis kit (Nzytech, Lisbon, Portugal), following the manufacturer's instructions. Gene specific primers used for real time PCR reactions were the following: DNA (cytosine-5)-methyltransferase 1 (DNMT1): forward 5'-CTGCTGTGGAGAAACTGGAA-
3', reverse 5'-TGATTTCCGCCTCAATGATA-3'; methyl CpG binding protein 2 (Mecp2): forward 5'-ATATTTGA TCAATCCCCAGGG-3', reverse 5'-CTT AGGTGGTTTC TGCTCTC-3'; Histone deacetylase 1 (HDAC1): forward 5'-GACCCTGACAAACGCATCTC-3', reverse 5'-GTTC TTGCGACCACCTTCTC-3' and $\beta$-actin: forward $5^{\prime}$ GTGACGTTGACATCCGTAAAGA-3', reverse 5'-GCCG GACTCATCGTACTCC-3'. Quantitative RT-PCR was performed with $10 \mathrm{ng}$ of the cDNA, $400 \mathrm{nM}$ of each primer, and iQ SYBR Green Supermix (Bio-Rad, Hercules, CA, USA). PCR cycles were proceeded as follows: Taq activation $\left(95^{\circ} \mathrm{C}, 3 \mathrm{~min}\right)$, denaturation $\left(95^{\circ} \mathrm{C}\right.$, $15 \mathrm{~s})$, and annealing/extension $\left(57^{\circ} \mathrm{C}, 45 \mathrm{~s}\right)$ using the BioRad CFX 96 Real-time system, C1000 Thermal cyclerm (Bio-Rad, Hercules, CA, USA). Melting curve was obtained under $0.5^{\circ} \mathrm{C}$ increments every $5 \mathrm{~s}$, from $65^{\circ} \mathrm{C}$ to $95^{\circ} \mathrm{C}$, with fluorescence recording after each temperature increment to verify the specificity of the amplification. The relative mRNA levels were estimated using the Bio-Rad CFX manager 2.1 software using $\beta$-actin as a reference gene.

\section{Quantification of $\beta$-catenin levels}

Single-plane confocal images were obtained using an inverted Zeiss LSM 710 confocal microscope, equipped with a Plan-ApoChromat $40 \times / 1.4$ NA oil-immersion objective to quantify $\beta$-catenin levels (33 images ( $n=1-2$ cells/image for a total of 43 cells from 6 mice), 34 images $(n=1-2$ cells/images for a total of 43 cells from 6 mice) for saline and $\mathrm{CV}$, respectively; (from $-3.52 \mathrm{~mm}$ to bregma $-1.34 \mathrm{~mm}$ [13]). Fiji software [14] was used to analyze confocal images and an ImageJ macro was created to select the nuclei and soma of DG immature neurons. A second macro was then developed to further select the cytoplasm, by subtracting the region of interest (ROI) corresponding the nuclei from the ROI corresponding to the soma. A final macro was designed to quantify single cell mean integrated density of $\beta$-catenin signals, determined at all possible thresholds, and divided by the respective area (published in [55], with some modifications). Results are presented as both the integrate density curves for thresholds 1 to 50 and as the area under the curve (AUC) of these curves (corresponding to the maximum intensity of $\beta$-catenin signal).

\section{Statistical analysis}

Data are expressed as means \pm standard error of the mean (SEM). Statistical significance was determined using One-Way analysis of variance (One-way ANOVA) with repeated measures ANOVA followed by Bonferroni post hoc test (Scholl Analysis), unpaired student's $t$ test for data passing normality tests or non-parametric Mann-Whitney test for data without normal distribution. $p$-values $<0.05$ were considered statistically significant. Statistical analysis 
was performed using GraphPad Prism Software (San Diego, CA, USA) or SPSS for Windows (SPSS Inc., Chicago, IL).

\section{Abbreviations}

3D: three dimensional; AD: Alzheimer's disease; ATR-FTIR: Attenuated Total Reflectance Infrared Spectroscopy; BSA: bovine serum albumin; CA3: Cornu Ammonis 3; CAT: catalase; CV: Coriolus versicolor; DCX: doublecortin; DG: dentate gyrus; EC: entorhinal cortex; EE: environmental enrichment; GCL: granular cell layer; HD: Huntington's disease; IL-1 $\beta$ : interleukin-

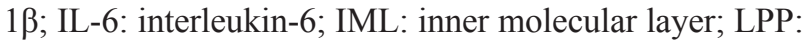
lateral perforant path; ML: molecular layer; MPP: medial perforant path; O.N.: overnight; O/MML: outer and medial molecular layer; PBS: phosphate buffered saline; PD: Parkinson's disease; PSD95: postsynaptic density protein 95; ROS: reactive oxygen species; RT: room temperature; SEM: standard error of the mean; SGZ: subgranular zone; SOD: superoxide dismutase; TNF- $\alpha$ : tumor necrosis factoralpha.

\section{Author contributions}

EF and IRP administered and monitored animals; performed the immunohistochemistry experiments and data analysis. NFR prepared CV powder for administration. SIM performed quantitative RT-PCR. JV designed the computer code for image processing and quantification of $\beta$-catenin levels. EF, IRP, FCP and ACR wrote the paper. FCP and ACR directed the project. TF, VC and CFR contributed with scientific expertise and revisions of the paper.

\section{CONFLICTS OF INTEREST}

The authors declare no potential conflicts of interest.

\section{FUNDING}

This work was supported by Mycology Research Laboratories, Ltd. This work was financed by the European Regional Development Fund (ERDF), through the Centro 2020 Regional Operational Programme under projects CENTRO-01-0145-FEDER-000012-HealthyAging2020 and CENTRO-01-0145-FEDER-000008 - BrainHealth 2020, and through the COMPETE 2020 - Operational Programme for Competitiveness and Internationalisation and Portuguese national funds via FCT - Fundação para a Ciência e a Tecnologia, under project POCI-010145-FEDER-007440 and Strategic Project 2015- UID/ NEU/04539/2013. EF and SIM are holders of FCT postdoctoral grant (SFRH/BPD/86551/2012 and SFRH/ BPD/99219/2013, respectively). J.V. salary was supported by an Ikerbasque Research Fellow grant.

\section{REFERENCES}

1. Valero J, Paris I, Sierra A. Lifestyle Shapes the Dialogue between Environment, Microglia, and Adult Neurogenesis. ACS Chem Neurosci. 2016; 7:442-453.

2. Gu Y, Janoschka S, Ge S. Neurogenesis and hippocampal plasticity in adult brain. In: Belzung C, Wigmore $\mathrm{P}$, (eds). Neurogenesis and Neural Plasticity. Current Topics in Behavioral Neurosciences. Springer, Berlin, Heidelberg; 2012; 15:117-142.

3. Piatti VC, Ewell LA, Leutgeb JK. Neurogenesis in the dentate gyrus: carrying the message or dictating the tone. Front Neurosci. 2013; 7:50.

4. Hanse E, Gustafsson B. Long-term Potentiation and Field EPSPs in the Lateral and Medial Perforant Paths in the Dentate Gyrus In Vitro: a Comparison. Eur J Neurosci. 1992; 4:1191-1201.

5. Ma DK, Marchetto MC, Guo JU, Ming GL, Gage FH, Song H. Epigenetic choreographers of neurogenesis in the adult mammalian brain. Nat Neurosci. 2010;13:1338-44.

6. Lie DC, Colamarino SA, Song HJ, Désiré L, Mira H, Consiglio A, Lein ES, Jessberger S, Lansford H, Dearie AR, Gage FH. Wnt signalling regulates adult hippocampal neurogenesis. Nature. 2005;437:1370-5.

7. Varela-Nallar L, Inestrosa NC. Wnt signaling in the regulation of adult hippocampal neurogenesis. Front Cell Neurosci. 2013; 7:100.

8. Yu X, Malenka RC. Beta-catenin is critical for dendritic morphogenesis. Nat Neurosci. 2003; 6:1169-77.

9. Abdul QA, Yu BP, Chung HY, Jung HA, Choi JS. Epigenetic modifications of gene expression by lifestyle and environment. Arch Pharm Res. 2017;40:1219-1237.

10. Tarapore RS, Siddiqui IA, Mukhtar H. Modulation of Wnt/ $\beta$-catenin signaling pathway by bioactive food components. Carcinogenesis. 2012; 33:483-491.

11. Hobbs C. Medicinal Mushrooms: An Exploration of Tradition, Healing and Culture. Santa Cruz (CA): Botanica Press; 1995.

12. Saleh MH, Rashedi I, Keating A. Immunomodulatory Properties of Coriolus versicolor: The Role of Polysaccharopeptide. Front Immunol. 2017; 8:1087.

13. Shi SH, Yang WT, Huang KY, Jiang YL, Yang GL, Wang $\mathrm{CF}$, Li Y. $\beta$-glucans from Coriolus versicolor protect mice against $\mathrm{S}$. typhimurium challenge by activation of macrophages. Int J Biol Macromol. 2016; 86:352-361.

14. Sun X, Sun Y, Zhang Q, Zhang H, Yang B, Wang Z, Zhu W, Li B, Wang Q, Kuang H. Screening and comparison of antioxidant activities of polysaccharides from Coriolus versicolor. Int J Biol Macromol. 2014; 69:12-19.

15. Ferrão J, Bell V, Calabrese V, Pimentel L, Pintado M, Fernandes TH. Impact of Mushroom Nutrition on Microbiota and Potential for Preventive Health. J Food Nutr Res. 2017; 5:226-33. 
16. Barros AB, Ferrão J, Fernandes T. A safety assessment of Coriolus versicolor biomass as a food supplement. Food Nutr Res. 2016; 60:29953.

17. Trovato A, Siracusa R, Di Paola R, Scuto M, Fronte V, Koverech G, Luca M, Serra A, Toscano MA, Petralia A, Cuzzocrea S, Calabrese V. Redox modulation of cellular stress response and lipoxin A4 expression by Coriolus versicolor in rat brain: Relevance to Alzheimer's disease pathogenesis. Neurotoxicology. 2016; 53:350-358.

18. Fang X, Jiang Y, Ji H, Zhao L, Xiao W, Wang Z, Ding G. The Synergistic Beneficial Effects of Ginkgo Flavonoid and Coriolus versicolor Polysaccharide for Memory Improvements in a Mouse Model of Dementia. Evid Based Complement Alternat Med. 2015; 2015:128394.

19. Bologna-Molina R, Mosqueda-Taylor A, Molina-Frechero N, Mori-Estevez AD, Sanchez-Acuna G. Comparison of the value of PCNA and Ki-67 as markers of cell proliferation in ameloblastic tumors. Med Oral Patol Oral Cir Bucal. 2013; 18:e174-9.

20. Francis F, Koulakoff A, Boucher D, Chafey P, Schaar B, Vinet MC, Friocourt G, McDonnell N, Reiner O, Kahn A, McConnell SK, Berwald-Netter Y, Denoulet P, Chelly J. Doublecortin is a developmentally regulated, microtubuleassociated protein expressed in migrating and differentiating neurons. Neuron. 1999; 23:247-256.

21. Gleeson JG, Lin PT, Flanagan LA, Walsh CA. Doublecortin is a microtubule-associated protein and is expressed widely by migrating neurons. Neuron. 1999; 23:257-271.

22. Encinas JM, Sierra A, Valcárcel-Martín R, Martín-Suárez S. A developmental perspective on adult hippocampal neurogenesis. Int J Dev Neurosci. 2013; 31:640-645.

23. Plumpe T, Ehninger D, Steiner B, Klempin F, Jessberger S, Brandt M, Romer B, Rodriguez GR, Kronenberg G, Kempermann G. Variability of doublecortin-associated dendrite maturation in adult hippocampal neurogenesis is independent of the regulation of precursor cell proliferation. BMC Neurosci. 2006; 7:77.

24. Rosenzweig S, Wojtowicz JM. Analyzing dendritic growth in a population of immature neurons in the adult dentate gyrus using laminar quantification of disjointed dendrites. Front Neurosci. 2011; 5:34.

25. Valero J, Mastrella G, Neiva I, Sánchez S, Malva JO. Longterm effects of an acute and systemic administration of LPS on adult neurogenesis and spatial memory. Front Neurosci. 2014; 8:83.

26. Benarroch EE. Adult neurogenesis in the dentate gyrus: general concepts and potential implications. Neurology. 2013; 81:1443-52.

27. Scharfman HE. The enigmatic mossy cell of the dentate gyrus. Nat Rev Neurosci. 2016; 17:562-75.

28. Arenaza-Urquijo EM, Wirth M, Chetelat G. Cognitive reserve and lifestyle: moving towards preclinical Alzheimer's disease. Front Aging Neurosci. 2015; 7:134.
29. Soloveva MV, Jamadar SD, Poudel G, Georgiou-Karistianis N. A critical review of brain and cognitive reserve in Huntington's disease. Neurosci Biobehav Rev. 2018; 88:155-169.

30. Miquel S, Champ C, Day J, Aarts E, Bahr BA, Bakker M, Bánáti D, Calabrese V, Cederholm T, Cryan J, Dye L, Farrimond JA, Korosi A, et al. Poor cognitive ageing: Vulnerabilities, mechanisms and the impact of nutritional interventions. Ageing Res Rev. 2018; 42:40-55.

31. Cespón J, Miniussi C, Pellicciari MC. Interventional programmes to improve cognition during healthy and pathological ageing: Cortical modulations and evidence for brain plasticity. Ageing Res Rev. 2018; 43:81-98.

32. Stern Y. Cognitive reserve in ageing and Alzheimer's disease. Lancet Neurol. 2012; 11:1006-1012.

33. Hindle JV, Hurt CS, Burn DJ, Brown RG, Samuel M, Wilson KC, Clare L. The effects of cognitive reserve and lifestyle on cognition and dementia in Parkinson's disease-a longitudinal cohort study. Int J Geriatr Psychiatry. 2016; 31:13-23.

34. Bonner-Jackson A, Long JD, Westervelt H, Tremont G, Aylward E, Paulsen JS, and PREDICT-HD Investigators and Coordinators of the Huntington Study Group. Cognitive reserve and brain reserve in prodromal Huntington's disease. J Int Neuropsychol Soc. 2013; 19:739-50.

35. Stern Y. What is cognitive reserve? Theory and research application of the reserve concept. J Int Neuropsychol Soc. 2002; 8:448-460.

36. Ninkovic J, Mori T, Götz M. Distinct Modes of Neuron Addition in Adult Mouse Neurogenesis. J Neurosci. 2007; 27:10906-10911.

37. Tronel S, Fabre A, Charrier V, Oliet SH, Gage FH, Abrous DN. Spatial learning sculpts the dendritic arbor of adultborn hippocampal neurons. Proc Natl Acad Sci USA. 2010; 107:7963-68.

38. Kempermann G. The neurogenic reserve hypothesis: what is adult hippocampal neurogenesis good for? Trends Neurosci. 2008; 31:163-9.

39. Radic T, Jungenitz T, Singer M, Beining M, Cuntz H, Vlachos A, Deller T, Schwarzacher SW. Time-lapse imaging reveals highly dynamic structural maturation of postnatally born dentate granule cells in organotypic entorhinohippocampal slice cultures. Sci Rep. 2017; 7:43724.

40. Zhao C, Teng EM, Summers RG Jr, Ming GL, Gage FH. Distinct morphological stages of dentate granule neuron maturation in the adult mouse hippocampus. J Neurosci. 2006; 26:3-11.

41. Garthe A, Kempermann G. An old test for new neurons: refining the Morris water maze to study the functional relevance of adult hippocampal neurogenesis. Front Neurosci. 2013; 7:63.

42. Pallas-Bazarra N, Jurado-Arjona J, Navarrete M, Esteban JA, Hernández F, Ávila J, Llorens-Martín M. Novel function of Tau in regulating the effects of external stimuli 
on adult hippocampal neurogenesis. EMBO J. 2016; 35:1417-36.

43. Zhang XQ, Mu JW, Wang HB, Jolkkonen J, Liu TT, Xiao T, Zhao M, Zhang CD, Zhao CS. Increased protein expression levels of pCREB, BDNF and SDF-1/CXCR4 in the hippocampus may be associated with enhanced neurogenesis induced by environmental enrichment. Mol Med Rep. 2016; 14:2231-2237.

44. Valero J, España J, Parra-Damas A, Martín E, RodríguezÁlvarez J, Saura CA. Short-term environmental enrichment rescues adult neurogenesis and memory deficits in $\mathrm{APP}(\mathrm{Sw}$, Ind) transgenic mice. PLoS One. 2011; 6:e16832.

45. MacDonald BT, Tamai K, He X. Wnt/ $\beta$-catenin signaling: components, mechanisms, and diseases. Dev Cell. 2009; 17:9-26.

46. Valenta T, Hausmann G, Basler K. The many faces and functions of $\beta$-catenin. EMBO J. 2012; 31:2714-2736.

47. Huber O, Korn R, McLaughlin J, Ohsugi M, Herrmann BG, Kemler R. Nuclear localization of beta-catenin by interaction with transcription factor LEF-1. Mech Dev. 1996; 59:3-10.

48. Kamiyama M, Horiuchi M, Umano K, Kondo K, Otsuka Y, Shibamoto T. Antioxidant/anti-inflammatory activities and chemical composition of extracts from the mushroom Trametes versicolor. International Journal of Nutrition and Food Sciences. 2013; 2:85-91.
49. Walton NM, Shin R, Tajinda K, Heusner CL, Kogan JH, Miyake S, Chen Q, Tamura K, Matsumoto M. Adult neurogenesis transiently generates oxidative stress. PLoS One. 2012; 7:e35264.

50. Yuan TF, Gu S, Shan C, Marchado S, Arias-Carrión O. Oxidative Stress and Adult Neurogenesis. Stem Cell Rev. 2015; 11:706-709.

51. Schindelin J, Arganda-Carreras I, Frise E, Kaynig V, Longair M, Pietzsch T, Preibisch S, Rueden C, Saalfeld S, Schmid B, Tinevez JY, White DJ, Hartenstein V, et al. Fiji: an open-source platform for biological-image analysis. Nat Methods. 2012; 9:676-82.

52. Paxinos G, Franklin KB. The Mouse Brain in Stereotaxic Coordinates. Gulf Professional Publishing; 2004.

53. Petreanu L, Alvarez-Buylla A. Maturation and death of adult-born olfactory bulb granule neurons: role of olfaction. J Neurosci. 2002; 22:6106-13.

54. Longair MH, Baker DA, Armstrong JD. Simple neurite tracer: open source software for reconstruction, visualization and analysis of neuronal processes. Bioinformatics. 2011; 27:2453-2454.

55. Matos CA, Nóbrega C, Louros SR, Almeida B, Ferreiro E, Valero J, Pereira de Almeida L, Macedo-Ribeiro S, Carvalho AL. Ataxin-3 phosphorylation decreases neuronal defects in spinocerebellar ataxia type 3 models. J Cell Biol. 2016; 212:465-80. 